\title{
TRADISI BUDAYA DAN KEARIFAN LOKAL PAULAK UNE DAN MANINGKIR TANGGA PADA PERNIKAHAN BATAK TOBA DI DESA SIGAPITON KECAMATAN AJIBATA: KAJIAN ANTROPOLINGUISTIK
}

\author{
Optapianty Situmorang ${ }^{1}$, Robert Sibarani ${ }^{2}$ \\ Universitas Sumatera Utara ${ }^{1}$, Universitas Sumatera Utara ${ }^{2}$ \\ pos-el: oktaviantysitumorang99@gmail.com ${ }^{1}$, robertsibarani02@gmail.com²
}

\begin{abstract}
ABSTRAK
Penelitian ini bertujuan untuk mengetahui tradisi Budaya dan Kearifan Lokal Paulak Une dan Maningkir Tangga pada pernikahan Batak Toba di Desa Sigapiton Kecamatan Ajibata. Riset inibetujuan untuk mendeskripsikan Tradisi Budaya dan Kearifan Lokal Paulak une dan Maningkir Tangga pada pernikahan dalam siklus kehidupan Batak Toba, Mendeskripsikan Performansi (Indeksiskalitas dan Partisipasi) tradisi Paulak Une dan Maningkir Tangga pada Pernikahan Batak Toba, Mendeskripsikan Kearifan Lokal yang terdapat dalam tradisi Paulak Une dan Maningkir Tangga pada pernikahan Batak Toba. Teori yang digunakan untuk menganalisis informasi riset ini merupakan teori antropolinguistik mencakup tradisi lisan, kearifan lokal, konsep Performansi (Indeksikalitas dan Partisipasi). Metode yang digunakan dalam penelitian ini adalah metode deskriptif. Hasil dari penelitian ini adalah: Terdapat 14 tradisi perrnikahan Batak Toba diantaranya termasuk Paulak Une dan Maningkir Tangga, terdapat 3 Performansi, 4 partisipasi, 5 indeksikalitas, dan 8 jenis kearifan lokal.
\end{abstract}

Kata Kunci : Paulak Une, Maningkir Tangga, Antropolinguistik

\section{ABSTRACT}

This study aims to determine the cultural traditions and local wisdom of Paulak Une and Maningkir Tangga at the Batak Toba wedding in Sigapiton Village, Ajibata District. This research aims to describe the Paulak une and Maningkir Tangga Cultural Traditions and Local Wisdom at marriages in the Toba Batak life cycle, to describe the performance (indexiscality and participation) of the Paulak Une and Maningkir Tangga traditions at Toba Batak marriages, to describe the local wisdom contained in the Paulak Une tradition and Maningkir Tangga at a Batak Toba wedding. The theory used to analyze this research information is an anthropolinguistic theory including oral tradition, local wisdom, the concept of Performance (Indexicity and Participation). The method used in this research is descriptive method. The results of this study are: There are 14 Toba Batak wedding traditions including Paulak Une and Maningkir Tangga, there are 3 performances, 4 participations, 5 indexicalities, and 8 types of local wisdom.

Keywords: Paulak Une, Maningkir Ladder, Anthropology.

\section{PENDAHULUAN}

Suku Batak Toba adalah salah satu bagian dari banyaknya suku-suku yang berada di Sumatera Utara. Suku Batak Toba memiliki eksistensi yang sangat eksis melalui budayanya. Mulai dari tarisi-tradisi nya, kebiasaaankebiasaannya serta adat isti adatnya hal ini dikemukakan oleh TM Sihombing dalam bukunya (1996) yang berjudul Adat Istiadat pernikahan Batak Toba Siklus kehidupan masyarakat Batak Toba, tersusun rapi mulai dari upacara kelahiran, pernikahan, hingga ke upacara kematian kutipan ini terdapat pada skripsi Sihite (2020) . Dalam ketiga siklus ini tentunya tidak hanya berjalan begitu saja namun 
semua berjalan sesai dengan adat istiadat yang sudah ditetapkan mulai dari nenek moyang nya. Dalam Skripsi Rianti Simbolon (2016) bahwa upacara tradisional suku Batak Toba terdapat di dalamnya satu garis besar yaitu uapacara adat pernikahan.

Wilayah masyarakat Batak Toba terbagi oleh 5 wilayah : Kabupaten Toba, Kabupaten Samosir, Kabupaten Tapanuli Utara, Kabupaten Humbang Hasundutan Dan Kabupaten Dairi. Dikala ini penulis lebih fokus terhadap wilayah Kabupaten Toba yang berkaitan dengan Tradisi perkawinannya beserta ruang lingkup siklus kehidupannya. Kabupaten Toba juga hasil dari Pemekaran Kabupaten Tapanuli Utara yang ditetapkan pada tahun 1999, Ibu kota kabupaten ini terletak di Kota Balige dan terdiri dari 16 kecamatan, salah satunya yaitu Kecamatan Ajibata yang penulis jadikan menjadi titik fokus untuk melakukan penelitian objek skripsi tepatnya di Desa Sigapiton.

Masyarakat Batak Toba khususnya masyarakat Sigapiton mengatakan bahwa perkawinan itu sangat penting karena untuk menunjang kebutuhan status sosial kedudukannya untuk acara adat yang lain seperti untuk uapacara kematian. Perkawinan pada suku Batak Toba bukan hanya semata mata untuk menggabung kedua gender yang berbeda, atau menggabung dua hati menjadi satu, tetapi juga untuk menggabungkan dua keluarga (paranak dan parboru) atau kerabat yang berbeda menjadi satu ikatan keluarga. Kutipan ini dikutip dalam pendapat Koentrajaningrat dalam bukunya hal 102 tahun 2007.

Pada dasarnya untuk pelaksanaan atau proses upacara pernikahan suku Batak Toba cukup memakan waktu yang lama. Namun dewasa ini hal tersebut sudah mulai hilang atau sudah tidak diterapkan dengan keasliannya. Dalam sebuah upacara adat pernikahan suku Batak Toba ada disebutkan tradisi paulak une dan maningkir tangga, yang biasanya acara ini dilaksanakan selang beberapa hari setelah pesta pernikahan ( pesta unjuk) selesai baru akan disusul untuk melakukan acara tersebut. Namun karena beberapa faktor yang tidak bisa medukung acara tersebut makan acara tradisi paulak une beserta maningkir tangga pun dimasukkan ke dalam acara satu hari atau ulaon sadari.

Faktor penyebab acara ini tidak dapat berlangsung dapat dilihat dari segi waktu, jarak, serta materi yang tidak memadai. Meski demikian masih ada beberapa daerah yang masih melaksanakan acara adat paulak une serta maningkir tangga di daerah Toba salah satunya di Desa Sigapiton. Maka muncul lah niat penulis ingin mengkaji bagaimana jalannya adat tersebut sesuai dengan keasliannya, sehingga bisa membantu atau menyelamatkan pengetahuan anak-anak muda suku Batak Toba, termasuk penulis yang hampir lupa atau bahkan tidak tahu dengan keaslian dari adat paulak une dan tingkir tangga. Tujuan dari penelitian ini adalah :

1. Mendeskripsikan bagaiamana tradisi paulak une dan maningkir tangga pada pernikahan Batak Toba.

2. Mendeskripsikan performansi (partisipasi dan indeksikalitas) yang terdapat dalam tradisi Paulak Une dan Maningkir Tangga pada pernikahan Batak Toba.

3. Mendeskripsikan kearifan lokal yang terdapat dalam tradisi Paulak Une dan Maningkir Tangga pada pernikahan Batak Toba.

\section{METODE PENELITIAN}

Metode yang penulis gunakan dalam penelitian ini adalah penelitian kualitatif yang bersifat deskriptif, Hal 
ini dikuatkan dengan pernyataan dari (Sibarani, 2014 : 279), menyatakan bahwa penelitian kualitatif adalah untuk mencari makna dan menggali nilai dari objek penelitiannya. Begitu juga dengan metode penelitian oleh Jhon Cress Wel (2016:3) menjelaskan bahwa metode penelitian merupakan rencana dan prosedur penelitian yang meliputi langkah-langkah berupa dari asumsi-asumsi luas hingga metodemetode terperinci dalam pengumpulan, analisis dan interprestasi data. adanya tanpa dimanipulasi, diatur dengan eksperimen atau test.

Teori yang penulis gunakan dalam penelitian ini ialah teori Antropolinguistik yaitu yang mencakup tradisi lisan, performansi ( partisipasi dan indeksikalitas ) beserta dengan kearifan lokalnya. Antropologi menurut Koentjaraningrat ialah ilmu yang mempelajari umat manusia pada umumnya dengan mempelajari aneka warna, bentuk fisik masyarakat serta kebudayaan yang dihasilkan. Sedangkan Antropologi menurut Haviland ialah studi mengenai umat manusia, yang berusaha menyusun generalisasi yang bermanfaat tentang manusia dan juga perilakunya serta agar dapat memperoleh pengertian yang bisa lengkap mengenai keanekaragaman manusia.

Sedangkan Kearifan lokal menurut Robert Sibarani (2014:114) dalam bukunya menyatakan bahwa "kearifan lokal adalah kebijaksanaan atau pengetahuan asli yang berasal dari nilai luhur tradisi budaya untuk mengatur tatanan kehidupan masyarakat. Kutipan ini juga terdapat pada skripsi Nababan, (2015) yang menyatakan bahwa untuk mencapai sebuah kerifan lokal harus didasari dengan dua bentuk yaitu kedamaian kesejahteraan

Sumber data dalam penelitian ini melaui informan dari masyarakat di lokai desa Sigapiton. Penelitian ini mengeksplorasi informasi secara mendetail yang digunakan peneliti dengan cara komunikasi langsung denganinforman. Sumber data merupakan suatu data dari mana data tersebut diperoleh. Sumber data yang diperoleh dalma penelitian ini ialah Data Primer. Data perimer adalah suatu data yang diperoleh dari sumbernya. Sumber primer dalam penelitian ini berupa informan dari Desa Sigapiton

Metode pengumpulan data adalahcara yang dilakukan peneliti untuk mengumpulkan dan menganalisis data yang diperoleh dari penelitian lapangan. Adapun metode pengumpulan data yang digunakan dalam penelitian yaitu: 1) Metode Observasi; Metode ini adalah metode yang dilakukan secara langsung ke daerah tempat penelitian untuk mendapatkan informasi data yang dibutuhkan. 2) Metode Wawancara; Metode wawancara adalah suatu metode yang digunakan penulis untuk memperoleh keterangan langsung dengan cara tanya jawab dengan informan. Penulis menggunakan dua macam teknik, yaitu: a) Teknik rekam: menggunakan ponsel. b) Teknik catat: mencatat nformasi tentang cerita yang disampaikan oleh informan dengan menggunakan buku dan alat tulis.

\section{HASIL DAN PEMBAHASAN}

Berdasarkan penelitian, maka penulis menyajikan hasil sebagai berikut:

\section{A. Tradisi Paulak Une dan Maningkir Tangga pada pernikahan etnik Batak Toba}

Pernikahan pada Batak Toba tersusu rapi mulai dari proses berkenalan hingga ke tahap berumah tangga hal ini ditemukan dalam buku Richard Sinaga. Berikut adalah proses awal hingga ke akhir pada pernikahan Batak Toba untuk menuju tradisi paulak une dan maningkir tangga antara lain

\section{Mangaririt atau mencari jodoh}

Tahap ini ialah untuk mencari perempuan idaman si laki-laki untuk 
dijadikan sebagai pasangan hidupnya. Cara ini dilaksanakan jika calon pengantin laki-laki tengah merantau atau bisa dikatakan tidak ada waktu untuk mencari perempuan untuk dirinya sendiri. Namun pada saaat ini tahap ini hampir hilang atau sudah siganti dengan istilah kata martandang bahkan di zaman teknologi saaat ini sudah banyak wadah untuk mencari pasangan misalnya pada aplikasi pencarian jodoh.

\section{Martukkar Tanda parbogason}

Untuk menunjukkan bahwa si lelaki telah bersungguh-sungguh untuk meminang si perempuan tersebut, sehingga dilakukanlah saling tukar barang seperti cincin dan kain sarung. Pada dasarnya hal ini bertujuan supaya kedua belah pihak saling yakin dan percaya bahwa pelangsungan pernikahan benar-benar akan terjadi.

\section{Marhori-hori dinding/marhusip}

Perundingan antara kedua belah pihak yang bisa dikatakan bersifat rahasia. Dikatakan bersifat rahasia karena akan ditakuti halhal yang tidak baik terjadi misalnya kegagalan atau harga mahar yang tidak saling cocok antara pebawaran dari kedua belah pihak tersebut.

\section{Martumpol}

Acara perjanjian calon pengantin yang dilaksanakan di depan imam dan jemat yang teraksana di dalam Gereja dan dihadiri oleh keluarga kedua calon mempelai tersebut. Acara ini wajib dihadiri oleh kedua pihak pihak, beserta undangan yang tidak terlalu banyak pesertanya.

\section{Manghatai tuhor/marhata sinamot}

Pada tahap ini akan dibahas mengenai mahar atau tuhor dari si perempuan tersebut. Masing-masing pihak akan mengutus parhata sinamotnya untuk saling melakukan negosiasi dari tuhor yang sudah dirundingkan waktu marhori-hori dingding. Dalam acara ini akan dibahas mengenai berapa jumlah ulos yang harus dipersiapkan dan daging apa yang akan disembelih untuk hajatan pesta unjuk nanti.

\section{Martonggo Raja}

Pada tahap ini akan dijelaskan bahwa dalam menjelang suatu pernikahan harus ada musyawarah antara pihak-pihak dari raja-raja kampung atau dalam istilah adat Batak disebut raja parhata atau natua-tua ni huta. Hal ini dilaksanakan agar kiranya pesta tersebut lancar dari awal hingga selesai. Dalam tahap ini akan dibagikan atau dihunjuk siapasiapa saja yang jadi protokol adat, parhobas dalam bagian memasak nasi, parhobas dalam bagian menyembelih daging, parhobas dalam bagian-bagian yang lain yang mendukung kelancaran pesta tersebut. Istilah parhobas dalam adat Batak diartikan sebagai orang yang membantu atau pihak komsumsi

\section{Manjalo Pamasu- \\ masuon Parbagason}

Pada tahap ini akan dijelaskan bahwa kedua pengantin akan dibawa ke Gereja untuk meminta berkat kepada Tuhan serta melakukan janji suci di depan jemat dan imam, bahwa mereka telah siap dan berjanji sebagai satu ikatan cinta dimana, mereka bukan lagi dua melainkan satu .

\section{Marunjuk/Ulaon Unjuk}

Setelah selesai pemberkatan pernikahan dari Gereja maka akan dilanjutkan dengan adat istiadat habatahon atau ruhut-ruhut paradaton yang berlaku secara adat Batak pada umumnya. Dalam acara ini nanti akan terjadi saling penyampaian ulos dari seluruh pihak yang sudah ditetapkan, penyampaian jambar, serta aturanaturan lainnya yang telah ditetapkan sesuai norma adat Batak.

\section{Dialap Jual}

Dialap jual terjadi karena ketika pesta unjuk dilaksanakan di tempat mempelai perempuan, sehingga setelah selesai acara adat pihak laki-laki akan 
langsung membawa perempuan tersebut ke rumah pihak mempelai laki-laki. Namun hal ini cukup jarang terjadi pada adat Batak dikarenakan tidak terlalu efisien terhadap materi atau jarak rumah antara kedua pengantin.

\section{Ditaruhon Jual}

Tahap ini menjelaskan bahwa ketika pesta unjuk atau acara adat dilaksanakan di tempat mempelai lakilaki maka perempuan tersebut pun akan diantar sesuai dengan norma yang berlaku. Bahwa ketika si perempuan tersebut ke rumah si mempelai laki-laki harus diantar oleh namboru (saudara perempuan dari bapak) dari si perempuan tersebut. Sehingga pihak mempelai laki-laki ketika melihat hal itu atau melihat namboru dari si perempuan terebut ikut mengantar, maka mereka harus memberi upa panaru atau upah untuk mengantar.

\section{Paulak Une}

Pada tahap ini adalah acara untuk temuh ramah secara adat oleh kedua keluarga belah pihak. Acara ini dilaksanakan di rumah pengantin perempuan, karena pada dasarnya paulak une tersebut adalah kunjungan adat keluarga laki-laki ke rumah orang tua perempuan. Sebagai manusia yang beradat mereka akan menyajikan makanan sebagai bawaaan mereka ke rumah keluarga perempuan tersebut.

Tahap ini selanjutnya akan dikupas secara mendalam bagaimana performansi, partisipasi, indeksikalitas serta kearifan lokal yang terdapat di dalamnya.

\section{Maningkir Tangga}

Pada tahap ini akan merujuk lebih ke balasan kunjungan dari pihak perempuan. Ketika acara paulak une sudah terlaksana, maka akan datang pihak perempuan untuk mengunjungi besan beserta pengantin baru ke rumah mempelai laki-laki tersebut secara adat. Pada tahap ini disebut lah itu acara tingkir tangga atau dengan kata lain untuk melihat keadaan tempat tinggal dari pengantin baru.

Sama sepert tradisi paulak une, tahap ini juga selanjutnya akan dibahas lebih mendalam bagaimana performansi, partisipasi, indeksikalitas serta kearifan lokal yang terdapat di dalamnya.

\section{Sirang jabu/manjae}

Dipajae atau manjae biasanya terjadi ketika pengantin baru merupakan bukan anak laki-laki bungsu atau siampudan. Mereka akan dipisahkan tempat tinggal, alat-alat rumah tanggga, dan seluruh perkakas yang mendukung rumah tangga mereka. Tetapi ketika pengantin baru laki-laki merupakan anak bungsu maka mereka tidak perlu manjae atau pisah rumah, sebab dalam istilah adat Batak yang mewarisi rumah dari orang tua tersebut adalah anak paling bungsu.

B. Performansi (Pertisipasi dan Indeksikalitas) Tradisi Paulak Une Dan Maningkir Tangga Pada Pernikahan Batak Toba

Performansi Tradisi Paulak Une dan Maningkir Tangga Pada Pernikahan Batak Toba

Performansi yang terdapat dalam tradisi paulak une dan maningkir tangga ialah :

\section{Pasahathon tudu- tudu ni sipanganon (menyampaikan makanan berupa adat)}

Bentuk Performansi dalam menyampaikan sipanganon na gok antara paranak dan parboru (keluarga pihak laki-laki dan keluarga pihak perempuan) antara lain sebagai berikut : Pasahathon tudu- tudu ni sipanganon (menyampaikan makanan berupa adat)

Tradisi Paulak une :"Di hamu raja ni hula-hula nami na huparsangapi hami. Di son pasahaton nami do tudutudu nisipanganon songon partanda somba ni roha nami tu hamu hula- 
hula nami. Tung songon $i$ pe nuaeng na hupasahat hami on, anggiat ma tudu-tudu ni na denggan on di hita saluhutna, lumobi ma di boru muna dohot anak nami na mamungka parsaripeon. Butima." . Adapun arti dari kutipan tersebut ialah : Untuk hulahula (besan) kami yang kami hargai/hormati .Disini kami akan menyerahkan berupa adat / sesuatu yang telah dilakukan oleh leluhur kita dari dulu sebagai pertanda persembahan kami untuk hula-hula (besan) kami..

Sementara performansi pasahathon tudu tudu nisipaganon dalam Tradisi maningkir tangga ialah : "Ido tutu raja ni boru. Songon na niida muna, ro hami hulahula muna tu bagas na martua on, mamboan boras sipir ni tondi. Pir ma tondi muna, lumobi boru dohot hela nami di na mamungka parsaripeon nasida. Huboan hami do dengke setio-tio, asa anggiat ma ro angka na tio dihita sude. hita hahipason dohot las ni roha tu angka ari na mangihut. Ima haroro nami raja ni boru. Butima. Adapun artinya ialah : Tujuan kedatangan kami adalah seperti yang kalian lihat kami datang disini membawa beras sebagai lambang kekuatan. Semoga menjadi berkat dan kekuatan baru bagi kita semua terutama untuk putri dan menantu kami dalam meulai rumah tangga baru. Kami disini membawa ikan mas ,semoga kita semakin diberkati kekedepannya.

\section{Makan Bersama}

Setelah selesai acara penyampaian makanan maka seluruh undangan dan kedua belah pihak pun makan bersama pada saat makan tersirat sebuah Umpasa : "Sititip ma sigompa golang-golang pangarahutna, Tung songon $i$ pe raja ni hula-hula sipanganon na tupa, sai godang ma pinasuna. Adapun maksud dari umpasa tersebut yaitu : Selamat menikmati hidangan kami yang tersedia apa adanya. Semoga mendapat berkat dan menjadi kesehatan bagi kita semua.

Pangkataion na marsintuhu (Pembicaraan penting dan formal)

Berikut Performansi pada saat melakukann pembicaraan formal (pangkation na marsintuhu):

Adapun performansi pangkataion na marsintuhu yang terdapat pada tradisi paulak unek dan maningkir tangga ialah: "Horas ma jalagabe raja ni hula-hula. Mauliate ma tapasahat tu Tuhan. Hipas hamu hudapot hami, hipas hami na ro mandapothon hamu. Mauliate do dokhonon nami di hamu hula-hula nami ala mansailas rohamuna huida hami manjalo haroro nami. Taringot tu haroro nami raja ni hula-hula tu bagas na martuaon, tangkas ma tutu pabotohonon. Tung na masihol do hami tu hamu, lumobi ma parumaen nami ima boru muna dohot hela muna. Asing nisihol nami $i$ raja nami, asa las tambai hamu poda na uli tu hela muna dohot tu parumaen nami tamba ni naung pinasahat muna. Asa lobi singkop jala gompis nasida diparsaripeon nasida tu ari na mangihu. Ima raja ni hula-hula haroro nami mandapothon hamu. Butima."

Adapun maksud dari bahasa batak tersebut yaitu : Kami dari keluarga pihak laki-laki mengucapkan terima kasih atas kesediaan waktu nya dan juga untuk pertanyaan tersebut. Dan keluarga pihak laki-laki pun menjawab tentang kedatangan mereka bahwa anak nya yang laki-laki telah bertemu dengan anak perempuan dari keluarga pihak perempuan di suatu tempat.

\section{Partisipasi dalam Tradisi Paulak Une dan Maningkir Tangga Pada Pernikahan Batak Toba}

Adapun pihak-pihak yang terlibat dalam tradisi paulak. une serta maningkir tangga pada pernikahan Batak. Toba adalah keluarga dari pihak...laki-laki (paranak ) dan keluarga dari pihak perempuan 
(parboru). Disamping itu untuk melancarkan sebuah acara adat istiadat Batak, tidak terlepas dari bantuan serta dorongan dari filsafah Dalihan Natolu yaitu mulai dari hula-hula atau tulang yang dilengkapi dengan dongan tubu, serta tidak lupa juga dengan boru ( saudara perempuan) yang cukup siap sedia dalam membantu segala kelancaran dan keperluan pesta. Disamping keberadaan dari tiga komponen utama itu, untuk melancarkan dan mensukseskan sebuah acara adat istiadat Batak Toba tidak terlepas dengan yang namanya dongan sahuta atau teman kerabat satu kampung.

Hula -hula (saudara laki-laki dari ibu)

Pada konteks ini hula-hula disebutkan pada urutan pertama karena termasuk dalam filosofi dari yang pertama atau yang terutama . Kedudukan hula-hula pada acara adat ini cukup penting meski tidak terlalu aktif saat berbicara tentang jalan nya adat tradisi paulak une dan tingkir tangga tersebut. Namun ketika boru telah berhasil menjalin hubungan baik dengan hula-hulanya, maka akan timbul pendapat bahwa si yang melaksanakan pesta adat tersebut sangat hormat dan kompak kepada saudara laki-lakinya.

\section{Dongan sabutuha atau kerabat satu marga}

Dongan sabutuha pada konteks ini cukup berperan aktif. Selama acara berlangsung dongan sabutuha sangat diharapkan untuk menyampaikan sepatah kata atau berupa nasehat-nasehat yang akan disampaikan kepada pengantin baru. Di samping itu dongan sabutuha juga cukup berperan penting dalam mengatur tata cara untuk lancarnya acara tersebut.

\section{Boru atau saudara perempuan dari laki-laki}

Posisi boru pada acara adat ini cukup penting, dan bisa dikatakan sangat penting. Karena yang bertugas untuk menyiapkan segala hidangan serta kelengkapan adalah bantuan dari pihak boru juga. Salah satunya diwaktu makan bersama tersebut, yang bertugas untuk membagi-bagikan hati dari daging serta potonganpotongan ikan mas tersebut adalah boru.

\section{Dongan Sahuta}

Dongan sahuta adalah orang yang merupakan kerabat satu kampung dari yang melaksanakan acara tersebut. Dongan sahuta juga termasuk salah satu orang yang terlibat dalam acara tradisi paulak une dan maningkir tangga.

Indeksikalitas Dalam Tradisi Paulak Une Dan Maningkir Tangga Pada Pernikahan Batak Toba

Indeks yang terdapat dalam tradisi paulak une dan maningkir tangga ialah sebagai berikut:

\section{Ikan mas (Dengke)}

Ikan mas disebut sebagai simbol keturunan dan kesuburan Karena ikan mas beranak tidak pernah satu-satu, tapi sekaligus sekali banyak, dan kalau berjalan itu selalu beriringan. Dengke juga berarti kumpulan makanan bersama nasi yang dibawa oleh parboru. Dengke yang diberikan hula hula kepada boru-nya yang mengadakan upacara paulak une atau marulaon adat yaitu : Dengke simudurudur, yakni dengke betina yang memiliki banyak telur atau dalam keadaan bertelur.

\section{Daging (Namarmiak miak)}

Dalam referensi namarmiak diartikan adalah binatang sigagat duhut atau disebut dengan hewan kerbau atau horbo dan babi. Namun dalam konteks paulak une dan maningkir tangga daging yang disajikan ialah daging babi. Sembelihan daging ini akan disajikan 
beserta tulang dan bagian besar untuk dijadikan jambar yang nantinya akan dibagi sesuai dengan kebutuhan status sosial masing-masing yang terdapat dalam adat dalihan natolu itu sendiri. Namarmiakmiak disiapkan oleh pihak paranak ketika melakukan adat paulak une sama halnya ketika tengah melakukan adat maningkir tangga.

\section{Tikar Pandan (Lage Tiar)}

Tikar yang dimaksud dalam indeksikalitas ini adalah tikar yang dipakai

saat upacara berlangsung. Seperti yang dipakai dalam upacara-upacara adat yang lain, tikar ini dibuat menjadi tempat duduk pengantin baru sebagai penghormatan kepada nenek moyang Batak dan duduk mengarah persembahan atau bahasa yang berlaku di desa Sigapiton ialah Telaga.

\section{Daun Sirih (Napuran)}

Napuran merupakan salah satu indeks yang digunakan dalam upacara acara paulak une. Napuran yang digunakan terdiri dari beberapa helai daun sirih yang diletakkan diatas pinggan na hot (piring). Perlu diketahui tanda ini diberikan dengan dasar bentuk fisik warna napuran tersebut adalah warna hijau sama seperti daun lainnya sehingga memunculkan interpretan yang melambangkan kesejukan dan hati yang tulus tanpa ada kebohongan dan kepura-puraan dari pihak 'hula-hula' yang telah memberikan berkat dan janji kepada mempelai dihadapan Tuhan.

\section{Beras (Boras Sipir Ni Tondi)}

Menurut beberapa informan dari hasil wawancara yang dilakukan di desa Sigapiton yakni boras berarti beras. Bentuk si adalah kata sandang. Kata pir berarti keras frasa si pir bermakna yang kuat. Tondi berarti jiwa atau roh. Berdasarkan arti setiap kata dan frasa itu, boras sipir ni tondi adalah beras untuk menguatkan roh atau jiwa penerima boras sipir ni tondi

\section{Kearifan Lokal Dalam Tradisi Paulak Une Dan Maningkir Tangga Pada Pernikahan Batak Toba}

Kearifan lokal yang terdapat dalam performansi tradisi Paulak une dan Maningkir tangga pada pernikahan Batak Toba ialah :

Tahap pasahathon tudu-tudu ni sipanganon

Tahap ini berfungsi untuk mempererat hubungan kedua keluarga tersebut serta memenuhi kaiah-kaidah yang sudah ada dalam adat Batak. Disertai dengan nilai kebersemaan dan kekeluargaan karena alam adat Batak kental dengan istilah kekerabatan serta rasa kebersamaan yang kental hal itu dapat dilihat dari faalsafah hidup orang Batak yaitu Dalihan Natolu . Disamping itu terdapat pula norma serta aturan yang berlaku dalam tahap pasahathon tudu-tudu ni sipanganon yaitu dalam tahap ini dimana dalam hal tradisi paulak une pihak laki laki membawa daging atau namarmiak - miak dan pihak perempuan menyediakan dengke sitio-tio atau ikan mas sedangkan pada acara maningkir tangga pihak perempuan membawa ikan mas (dengke siio-tio) dan pihak laki-laki menyediakan namarmiak-miak. Aturan ini terjadi karena itulah ruhut-ruhut yang sudah ditetapkan dalam adat dan Batak yang sesuai dengan kaidah habatakon atau adat Batak tersebut.

\section{Tahap makan bersama}

Makna yang terdapat dalam tahap ini ialah kedua belah pihak saling memberi makanan yang telah mereka sediakan untuk dimakan bersama. Hal ini berfungsi untuk mensyukuri atas bertemunya mereka dalam keadaan sehat serta untuk memenuhi terlaksananya istilah ruhut-ruhut siboanon tadi yang disertai dengan nilai syukur, kebersamaan serta nilai makan bersama. Pada tahap ini juga berlaku Norma 
beserta aturan yaitu boru dari pihak lakilaki harus membagi-bagikan aliang atau hati dari daging tersebut sedangkan untuk boru dari pihak perempuan akan membagi-bagikan dengke atau ikan mas tersebut tadi kepada seluruh undangan yang sedang makan bersama.Hal ini disebabkan untuk menghargai serta untuk menunjukkan rasa sayang si pembuat acara terhadap tamu beserta undangannya.

\section{Tahap pangkation namarsintuhu atau Pembicaraan penting dan formal}

Pada tahap dimaknai bahwa kedua belah pihak berkesempatan saling memberi interaksi terhadap pengantin baru yang berfungsi dan bertujuan untuk memberikan nasehat serta masukan-masukan terhadap pengantin baru sehingga munculnya nilai kekerabatan yang menggambarkan kehidupan serta filsafah hidup orang Batak. Namun disampping itu pada tahap ini juga terdapat norma beserta aturan yaitu pengantin baru wajib mangampu kepada kedua orang tua masing-masing arti meminta berkat serta meminta maaf bila ada kesalahankesalahan. Hal ini dikarenakan sebab disitulah pengantin baru memulai hidup baru serta lembaran baru sehingga perlu untuk melupakan segala masa lalu yang mungkin membuat hubungan anak dengan orang tua tersebut akan kurang akrab,sehingga akan lancar an abadi hubungan serta kekerabatan antar keluarga tersebut.

Dari semua makna, fungsi, norma dan nilai dari ketiga tahapan tersebut terdapat kearifan lokal yaitu: rasa syukur, kerukunan, kesopansantunan, kesetiakawanan sosial, kebersamaan, komitmen, kejujuran, penyelesaian konflik, serta pikiran positif tersebut yang akhirnya akan membentuk sebuah kedamaian.

\section{KESIMPULAN}

Berdasarkan uraian di atas dapat disimpulkan: Tradisi paulak une dan maningkir tanggga pada pernikahan batak toba : (1) Mangaririt Mangalehon Tanda (3) Marhusip (4) Martumpol (5) Marhata sinamot (6) Martonggo raja (7) Manjalo pasu pasu parbogason (8) Marunjuk (9) Dialap jual (10) Ditaruhon jual (11) Paulak une (12) Maningkir tangga (13) Manjae.

Performansi tradisi paulak une dan maningkir tangga pada pernikahan Batak Toba : Pasahathon tudu-tudu ni sipanganon (pemberian makanan berupa adat), makan bersama, pangakataion na marsintuhu ( pembicaraan formal). Partisipasi tradisi paulak une dan Maningkir tangga pada pernikahan Batak Toba : Hula-hula, Dongan Tubu, Boru, dongan sahuta. Indeks yang terdapat dalam tradisi paulak une dan maningkir tangga pada pernikahan Batak Toba ialah sebagai berikut : (1) Dengke simudur udur (2) Namarmiak-miak (3) Lage tiar (4) Napuran (5) Boras si pir ni tondi.

Kearifan lokal yang terdapat dalam tradisi paulak une dan maningir tangga:

1. Tahap pasahathon tudu-tudu ni sipanganon (pemberian makanan)

-Nilai : nilai kebersemaan

dan kekeluargaan

- Norma : Dalam hal tradisi paulak une pihak laki laki membawa daging atau namarmiak - miak dan pihak perempuan menyediakan dengke sitio-tio atau ikan mas sedangkan pada acara maningkir tangga pihak perempuan membawa ikan mas (dengke siio-tio) dan Pihak laki-laki menyediakan namarmiak-miak.

- Kearifan lokal : rasa syukur, kerukunan, kesopansantunan, kesetiakawanan sosial.

2. Tahap makan bersama

- Nilai : nilai syukur, kebersamaan serta nilai makan bersama

- Norma: aturan yang berlaku dalam tahap ini ialah boru dari pihak laki-laki harus membagi-bagikan aliang atau hati 
dari daging tersebut sedangkan untuk boru dari pihak perempuan akan membagi-bagikan dengke atau ikan mas tersebut

- Kearifan Lokal : rasa syukur serta kebersamaan

3. Tahap Pangkataion namarsintuhu (pemberian nasehat)

- Nilai : Nilai kekerabatan

- Norma : Aturan yang berlaku dalam tahap ini ialah pengantin baru wajib mangampu kepada kedua orang tua masing-masing arti meminta berkat serta meminta maaf bila ada kesalahankesalahan

- Kearifan lokal yang terdapat dalam tahap ini ilaah kearifan lokal komitmen, kejujuran, penyelesaian konflik, serta pikiran positif.

Hasil penelitian tentang tradisi budaya paulak une dan maningkir tangga pada pernikahan Batak Toba ini diharapkan dapat memberikan manfaat secara praktis dan nyata dalam kehidupan sehari-hari. Diharapkan penelitian ini dapat dimanfaatkan dalam kegiatan pembelajaran sastra yang secara khusus membahas tentang masalah tradisi budaya paulak une dan maningkir tangga.

\section{DAFTAR PUSTAKA}

Cresswell, W Jhon. Penelitian dan
Desain riset. Jakarta

Haviland, William A. (1999). pengantar Antropologi. Jakarta: Erlangga.

Koenjaraningrat. (1967). Sejarah Teori antropologi Jakarta: Universitas Indonesia

Koenjaraningrat. (2007). Adat istiadat pernikahan

Sibarani, dkk $=(2014: 25)$, Metode kualitatif

Sibarani, Robert, ( 2014: 114). Kearifan Lokal Hakikat, Peran dan metode Tradisi lisan .Jakarta : Asosiasi Tradisi Lisan.

Sihombing, TM (1996). Adat Istiadat Dalam Pernikahan Batak

Toba. Jakarta: Balai Pustaka.

Sinaga, Richard (2007:180).

Perkawinan Adat Dalihan

Natolu, Jakarta Dian Utama.

Nababan, (2015). Kearifan lokal

Tradisi Bertani pada masyarakat Batak Toba di Baktiraja.Kajian Tradisi Lisan Medan : Skripsi.

Sihite, (2020). Upacara Adat Martutu Aek pada Masyarakat Batak Kajian ntropolinguistik. Medan: Skripsi

Simbolon, Rianti (2016). "Upacara Tradisional Pada Etnik Batak Di Kabupaten Samosir" ( skripsi ). 